\title{
CRMP5-associated GTPase (CRAG) Is a Candidate Driver Gene for Colorectal Cancer Carcinogenesis
}

\author{
DAI SHIMIZU ${ }^{1,2}$, TAKAAKI MASUDA ${ }^{1}$, KUNIAKI SATO $^{1}$, YUSUKE TSURUDA ${ }^{1}$, HAJIME OTSU ${ }^{1}$, \\ YOSUKE KURODA ${ }^{1}$, HIDETOSHI EGUCHI $^{1}$, YASUHIRO KODERA ${ }^{2}$ and KOSHI MIMORI ${ }^{1}$ \\ ${ }^{1}$ Department of Surgery, Kyushu University Beppu Hospital, Beppu, Japan; \\ ${ }^{2}$ Department of Gastroenterological Surgery (Surgery II), \\ Nagoya University Graduate School of Medicine, Nagoya, Japan
}

\begin{abstract}
Background/Aim: Certain chromosomal arms are clonally amplified in colorectal cancer $(C R C)$ and may contain novel driver genes. The aim of this study was to identify a novel driver gene for colorectal cancer carcinogenesis on long arm of chromosome 7 and the clarify its biological function. Materials and Methods: We identified ArfGAP with GTPase domain, ankyrin repeat and $P H$ domain 3 (AGAP3) as a putative driver gene using the CRC dataset in The Cancer Genome Atlas (TCGA). Biological functions of AGAP3 and CRMP5-associated GTPase (CRAG), a splicing variant of AGAP3, were explored by overexpression. AGAP3/CRAG expression in our cohort was examined by quantitative reverse transcription polymerase chain reaction. Clinical significance of AGAP3/CRAG expression in TCGA dataset, Gene Expression Omnibus datasets and our clinical cohort was evaluated. Results: AGAP3 expression was significantly increased in CRC and colorectal adenoma compared to normal tissue. CRAG overexpression up-regulated c-Jun expression, and significantly increased cell proliferation and colony formation capability. AGAP3 expression did not have a concordant association with patient prognosis among datasets. Conclusion: CRAG may contribute to development of CRC via activator protein 1 activation.
\end{abstract}

Colorectal cancer (CRC) is one of the most frequently diagnosed cancers and a serious public health issue worldwide (1). The major process of $\mathrm{CRC}$ carcinogenesis is the adenoma-carcinoma sequence in which the accumulation of several somatic mutations drives stepwise tumorigenesis in the colorectum (2).

This article is freely accessible online.

Correspondence to: Koshi Mimori, MD, Ph.D., Department of Surgery, Kyushu University Beppu Hospital, 4546 Tsurumihara, Beppu 874-0838, Japan. Tel: +81 977271650, Fax: +81 977271651, e-mail: kmimori@beppu.kyushu-u.ac.jp

Key Words: Colorectal cancer, AGAP3, CRAG, AP-1, carcinogenesis.
Recently, the development of sequencing technology and multiregional analysis have shed light on intertumor and intratumor heterogeneity, mutation evolution and robust driver mutations in CRC $(3,4)$. Simultaneously, copy number alteration (CNA) of certain chromosomal arms was identified as the founder event of CRC carcinogenesis (3). On chromosomal arms that are fundamentally amplified in CRC, including the long arm of chromosome 7 (Chr.7q), novel potential driver genes that are overexpressed via copy number gain may be contained (5). In order to develop comprehensive and universal cancer therapeutic agents or biomarkers, the truncal features of carcinogenesis that drive malignant phenotypes should be targeted. This approach is promising due to the heterogeneous nature of malignancies.

Here, we aimed to identify a novel overexpressing driver gene on Chr.7q using a public dataset. AGAP3 was recognized as a putative driver gene. AGAP3 has several splicing variants, including $C R A G$ (Figure 1A). $C R A G$ reportedly has a particular function absent in $A G A P 3$, activating activator protein 1 (AP-1), which possesses oncogenic function in several cancers (6). In this study, the clinical significance and biological functions of $A G A P 3$ and $C R A G$ in CRC were investigated.

\section{Materials and Methods}

Public datasets of CRC and colorectal adenoma. DNA copy number data and RNA sequencing data of $615 \mathrm{CRC}$ patients and $58 \mathrm{CRC}$ cell lines were obtained from The Cancer Genome Atlas (TCGA) via Broad Institute's Firehose (http://gdac.broadinstitute.org) and Cancer Cell Line Encyclopedia (https://portals.broadinstitute.org/ccle), respectively. CRC expression array data and clinical information in GSE17538 and GSE21815 were obtained from Gene Expression Omnibus (GEO) (https://www.ncbi.nlm.nih.gov/geo/). Expression array data of colorectal adenomas in GSE8671 were obtained from GEO. In public datasets, $A G A P 3$ mRNA expression was evaluated regardless of the type of splicing variant.

Identification of putative driver genes in CRC. Using the DNA copy number and mRNA expression data from TCGA, putative driver genes on Chr.7q were identified that satisfied the following two criteria: 1) 
positive correlation between DNA copy number and mRNA expression (rho $>0.4, p<0.05$ ) and 2 ) higher expression in primary CRC tissues than in paired normal tissues (fold change $>2, p<0.05$ ).

CRC cell lines. Human CRC cell lines CaR-1, CCK81, colo320DM, DLD-1, and WiDr were obtained from JCBR cell bank (Osaka, Japan); colo205 and HCT116 were obtained from RIKEN BioResource Research Center (Ibaraki, Japan); and LS174T and RKO were obtained from the American Type Culture Collection (Manassas, VA, USA). All cell lines were cultured in appropriate medium supplemented with $10 \%$ fetal bovine serum at $37^{\circ} \mathrm{C}$ in an atmosphere containing $5 \% \mathrm{CO}_{2}$.

Overexpression of ArfGAP with GTPase domain, ankyrin repeat and PH domain 3 (AGAP3) and CRMP5-associated GTPase (CRAG). The expression constructs, within the pCMV5 vector, for AGAP3 tagged with HA and CRAG tagged with HA were graciously provided by the Laboratory of Molecular Biochemistry, School of Life Sciences, Tokyo University of Pharmacy and Life Sciences, Japan $(7,8)$. The expression constructs for AGAP3 and CRAG, a splicing variant of $A G A P 3$, within pCMV5, were transferred to CSII-CMV-MCS vector (RIKEN) due to the absence of an empty pCMV5 vector in our laboratory. Expression vectors were transiently transfected into DLD-1 and HCT116 cells using Lipofectamine 3000 (Invitrogen, Carlsbad, CA, USA) according to the manufacturer's protocol.

Clinical CRC samples. Primary CRC tissues and paired normal tissues were obtained from 61 patients who underwent surgical resection of primary tumor at Kyushu University Beppu Hospital and affiliated hospitals between 1992 and 2007. Clinical samples were immediately frozen with RNAlater (Ambion, Palo Alto, CA, USA) in liquid nitrogen and stored at $-80^{\circ} \mathrm{C}$ until use. All patients provided written informed consent, and the study protocol was approved by the local ethics review board of Kyushu University. Experiments with these samples were performed in accordance with the approved guidelines.

RNA extraction and quantitative reverse transcription polymerase chain reaction ( $q R T-P C R$ ). Total RNA was extracted using ISOGEN (Nippon Gene, Tokyo, Japan) according to the manufacturer's protocol. Synthesis of complementary DNA and qRT-PCR were performed as previously described, and $18 \mathrm{~S}$ ribosomal mRNA expression was quantified for standardization (9). In our own CRC cohort and CRC cell lines, AGAP3 (NM_001350102.1) and CRAG (NM_001350102.1) mRNA expression levels were calculated separately. The specific primers are listed in Table I.

Protein extraction and western blotting (WB). Cells were lysed in lysis buffer, and protein expression was evaluated by WB as previously described (10). A primary mouse monoclonal antibody against HA (H9658; Sigma-Aldrich, St. Louis, MO, USA), a primary rabbit monoclonal antibody against c-Fos (\#2250; Cell Signaling Technology, Beverly, MA, USA) and a primary rabbit monoclonal antibody against c-Jun (\#9165; Cell Signaling Technology) were used at dilutions of 1:10000, 1:500 and 1:1000, respectively, in $5 \%$ milk at $4^{\circ} \mathrm{C}$ overnight. A primary mouse monoclonal antibody against $\beta$-actin (sc-47778; Santa Cruz Biotechnology, Dallas, TX, USA) was used at a dilution of 1:1000 at room temperature for $1 \mathrm{~h}$.
Table I. Sequences of specific primers.

\begin{tabular}{lll}
\hline Gene symbol & Type & Sequence \\
\hline \multirow{2}{*}{ AGAP3 } & Forward & 5'-CCTGAGCTCCAGTTTGCTGC-3' \\
& Reverse & 5'-GCTGATGGCATCCTGCGT-3' \\
CRAG & Forward & 5'-ATCAACCAGGCCACGAATGG-3' \\
& Reverse & 5'-GGAAACAGTGGCACATATCGTGAAG-3' \\
$18 S$ & Forward & 5'-AGTCCCTGCCCTTTGTACACA-3' \\
& Reverse & 5'-CGATCCGAGGGCCTCACTA-3' \\
\hline
\end{tabular}

Cell proliferation and colony formation assay. The cell proliferation capacity was evaluated by MTT assays using Cell Proliferation Kit 1 (Roche Applied Science, Penzberg, Germany) according to the manufacturer's protocol. Cells $\left(2 \times 10^{4}\right.$ cells per well $)$ were seeded into 24-well plates. The optical density of each well was measured in technical triplicates and biological triplicates on days $0-5$. For colony formation assays, cells $\left(5 \times 10^{2}\right.$ cells per well) were seeded into 6-well plates. After 14 days, the number of colonies was counted under an inverted microscope.

Statistical analysis. Differences in continuous variables were tested using Student's $t$-tests. Correlations between two groups were evaluated by Pearson's product moment correlation coefficient. Survival time was evaluated using the Kaplan-Meier method, and survival curves were compared using log-rank tests. All statistical analyses were performed using R version 3.4.1 (Vienna, Austria. URL: http://www.R-project.org/).

\section{Results}

Identification of AGAP3 as a putative driver gene in CRC. First, CNA of chromosomal arms occurred at the initial phase of carcinogenesis in CRC was confirmed using the TCGA dataset. The copy numbers of certain chromosomal arms, such as 7p, 7q, 8q, 13p, 13q, 17p, 18p, 18q and 20q, were frequently altered in advanced CRC as well as in Stage I CRC (Figure 1B). Focusing on Chr.7q, 44 putative driver genes were identified according to the criteria (Figure 1C and D). In this study, it was determined that AGAP3 encodes an essential component of the $N$-methyl-D-aspartate (NMDA) receptor signaling complex in synapses that has not been previously associated with malignancies, including CRC (11).

CNA and MRNA expression of AGAP3 in a public dataset. The focal DNA copy number in the AGAP3 locus was positively correlated with $A G A P 3$ mRNA expression in TCGA dataset $(\mathrm{rho}=0.493, p<0.001)$ and the CCLE dataset (rho $=0.503, p<0.001$ ). In addition, DNA copy number in the AGAP3 locus was increased in many samples in both TCGA and CCLE datasets (Figure 2A and B), indicating that $A G A P 3$ is overexpressed via the $7 \mathrm{q}$ copy number gain in CRC. AGAP3 mRNA expression was significantly higher in 
A

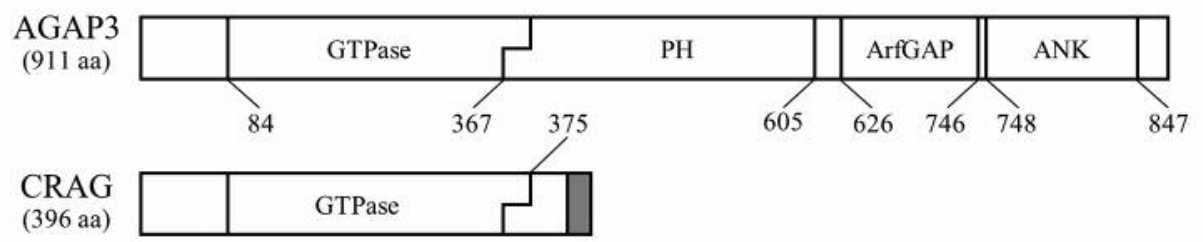

B
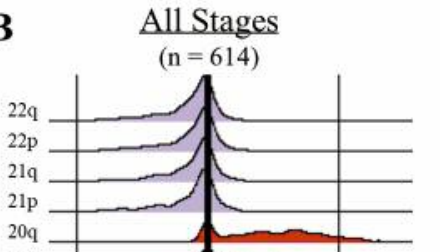

$20 \mathrm{p}$

$19 \mathrm{q}$

$19 \mathrm{p}$

18p

$17 \mathrm{p}$

$16 \mathrm{q}$

$16 \mathrm{p}$

$15 \mathrm{q}$
$15 \mathrm{p}$

$14 \mathrm{q}$

$13 \mathrm{q}$

$13 \mathrm{p}$

$12 \mathrm{q}$
$12 \mathrm{p}$

$11 \mathrm{q}$

$11 \mathrm{p}$

$10 \mathrm{q}$

$9 \mathrm{q}$

$9 \mathrm{p}$

$8 \mathrm{q}$

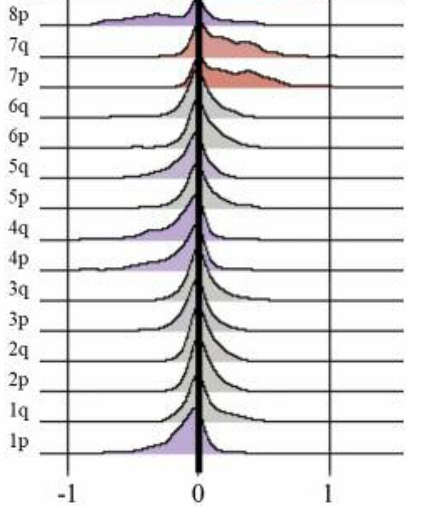

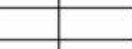

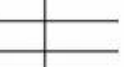

(n)
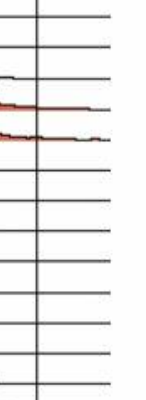

$+$

1
Copy

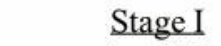

$(\mathrm{n}=105)$

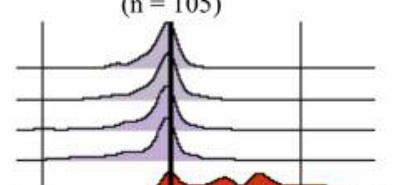

\section{西}
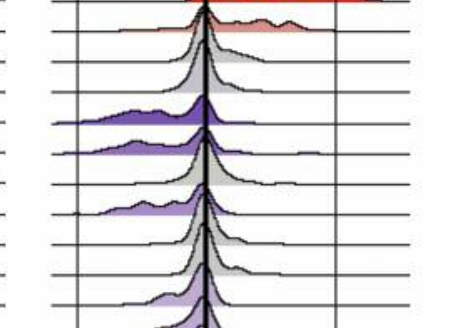
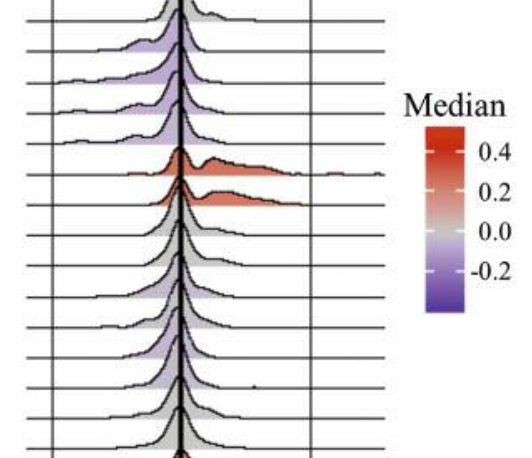

$-1$
C

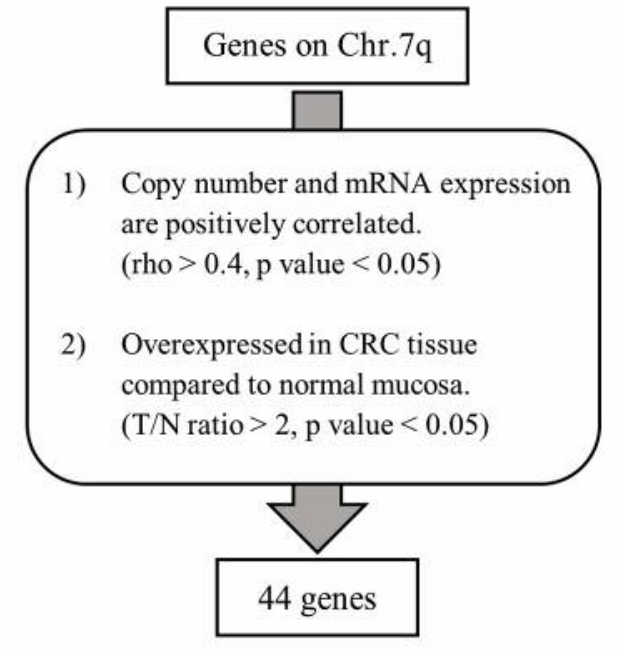

D

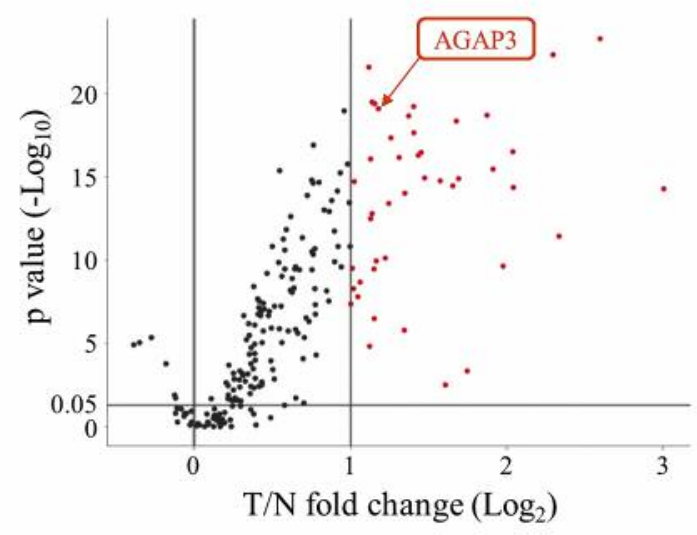

Figure 1. Identification of the putative driver gene on chromosome 7q. A: Structure of AGAP3 and CRAG. The gray box indicates a different sequence from AGAP3. B: CNA of the chromosomal arm in the TCGA dataset. C: Schematic diagram of the criteria for putative driver gene identification. D: Volcano plot of comparison between CRC tissue and paired normal colorectal tissue in TCGA dataset. Red plots indicate the genes that satisfy the criteria; overexpressed in CRC tissue compared to that in normal mucosa $(T / N$ ratio $>2, p$-value $<0.05)$.

CRC tissues than in paired normal tissues in TCGA dataset (fold change $=2.26, p<0.001$ ), but there were no significant differences among UICC pathological stages (Figure $2 \mathrm{C}$ and D). In the GSE8671 dataset, $A G A P 3$ mRNA expression was significantly higher in colorectal adenoma tissues than in paired normal tissues $(p=0.001)$ (Figure $2 \mathrm{E}$ ). These data suggest that AGAP3 overexpression plays an important role in the initial phase of carcinogenesis. 


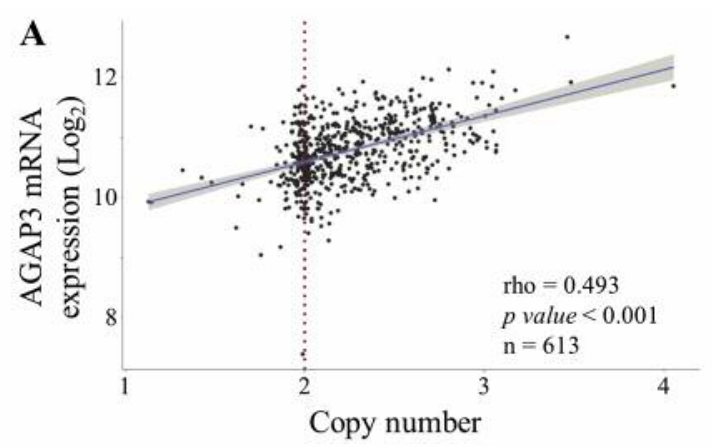

C

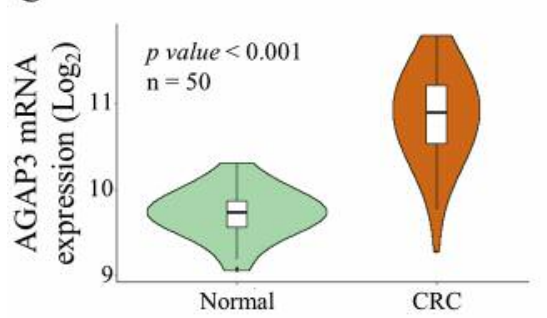

D

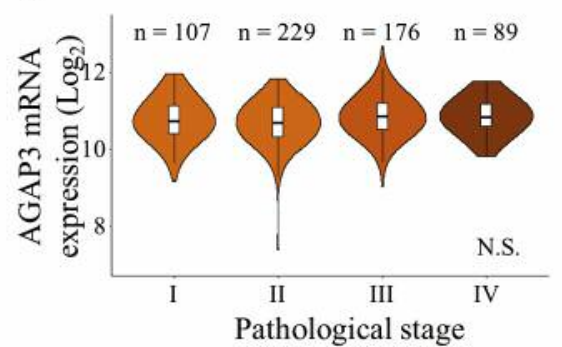

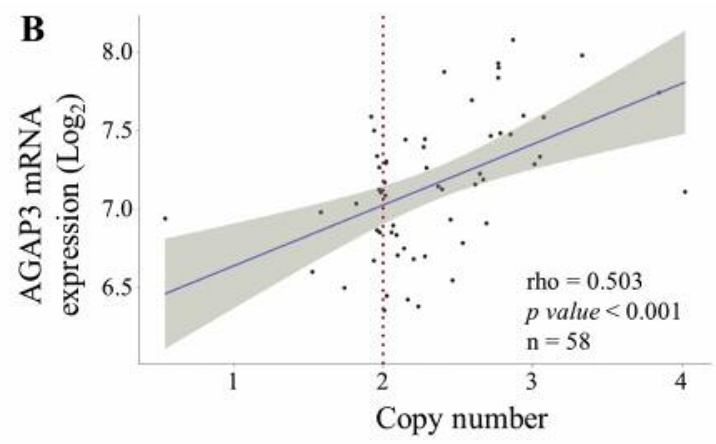

$\mathbf{E}$

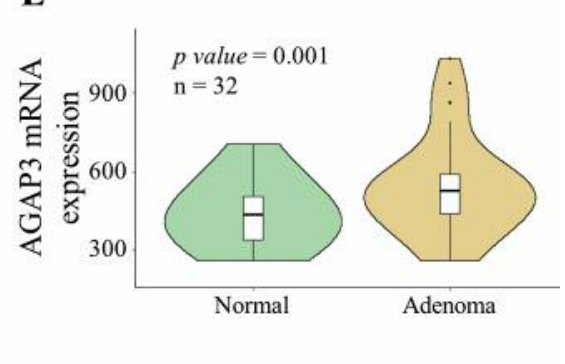

Figure 2. CNA and mRNA expression of AGAP3 in public datasets. A: Correlation between the focal DNA copy number in the AGAP3 locus and AGAP3 mRNA expression in TCGA dataset. B: Correlation between the focal DNA copy number in the AGAP3 locus and AGAP3 mRNA expression in the CCLE dataset. C: AGAP3 mRNA expression in CRC tissue and paired normal colorectal tissue in TCGA dataset. D: AGAP3 mRNA expression in CRC tissue divided by pathological stage. E: AGAP3 mRNA expression in colorectal adenoma and paired normal colorectal tissue in the GSE8671 dataset.

The effects of AGAP3 and CRAG overexpression on carcinogenesis. AGAP3 and CRAG mRNA expression in CRC cell lines is shown in Figure 3A and 3B. DLD-1 and HCT116 were selected for overexpression experiments due to twodimensional growth and transfection efficacy in a preliminary experiment using an expression vector carrying EGFP (Figure 3C). Overexpression of HA-AGAP3 or HA-CRAG was confirmed by WB (Figure 3D). To verify the effect of $A G A P 3$ and $C R A G$ on carcinogenesis, variations in cell proliferation and colony formation capability were explored by overexpression experiments. HA-CRAG overexpression significantly increased the cell proliferation of DLD-1 and HCT116 and the colony formation capability of HCT116, while HA-AGAP3 overexpression did not induce an increase in cell proliferation and colony formation capability (Figure 3E-H). To clarify a part of the mechanism underlying the increase in cell proliferation, the effect of AGAP3 and CRAG overexpression on AP-1 was investigated. c-Jun was markedly up-regulated by HA-CRAG overexpression and slightly up-regulated by HA-AGAP3 overexpression (Figure 3I). c-Fos was undetectable without stimulation in our CRC cells.

Clinical significance of AGAP3 and CRAG mRNA expression. In TCGA dataset, patients with high $A G A P 3$ mRNA expression had significantly poorer overall survival (OS) $(p=0.003)$ (Figure 4A). However, patients with high AGAP3 mRNA expression had significantly better OS in the GSE17538 and
GSE21815 datasets ( $p=0.019$ and $p=0.021$, respectively) (Figure 4B, C). The prognostic impact of $A G A P 3$ mRNA expression, that was evaluated regardless of the splicing variants, differed among datasets (Figure 4A-C). When the splicing variants were evaluated separately, the expression of $A G A P 3$ and $C R A G$ mRNA was not found to be associated with OS ( $p=0.69$ and $p=0.42$, respectively) (Figure 4D and E). Moreover, there was no significant association between AGAP3 or $C R A G$ mRNA expression and clinicopathological features in our clinical cohort (Table II). Thus, AGAP3 and CRAG should have more oncogenic effects on carcinogenesis and less oncogenic effects on CRC progression.

\section{Discussion}

In the present study, $C R A G$, a splicing variant of $A G A P 3$, was identified as a putative driver gene of $C R C$ carcinogenesis and was demonstrated to contribute to tumor growth. To the best of our knowledge, this study is the first to explore the biological function of $A G A P 3$ and $C R A G$ in malignancy. $A G A P 3$ reportedly evokes NMDA receptor activation, which induces synaptic trafficking of the AMPA receptor (11). The AGAP3 protein contains an $N$-terminal GTPase-like domain, a pleckstrin homology domain, an ArfGAP domain and several $C$-terminal ankyrin repeat domains. $C R A G$ has a structure cleaved from the 3' prime end in the middle of the pleckstrin homology domain of $A G A P 3$. Qin Q et al. reported that CRAG 

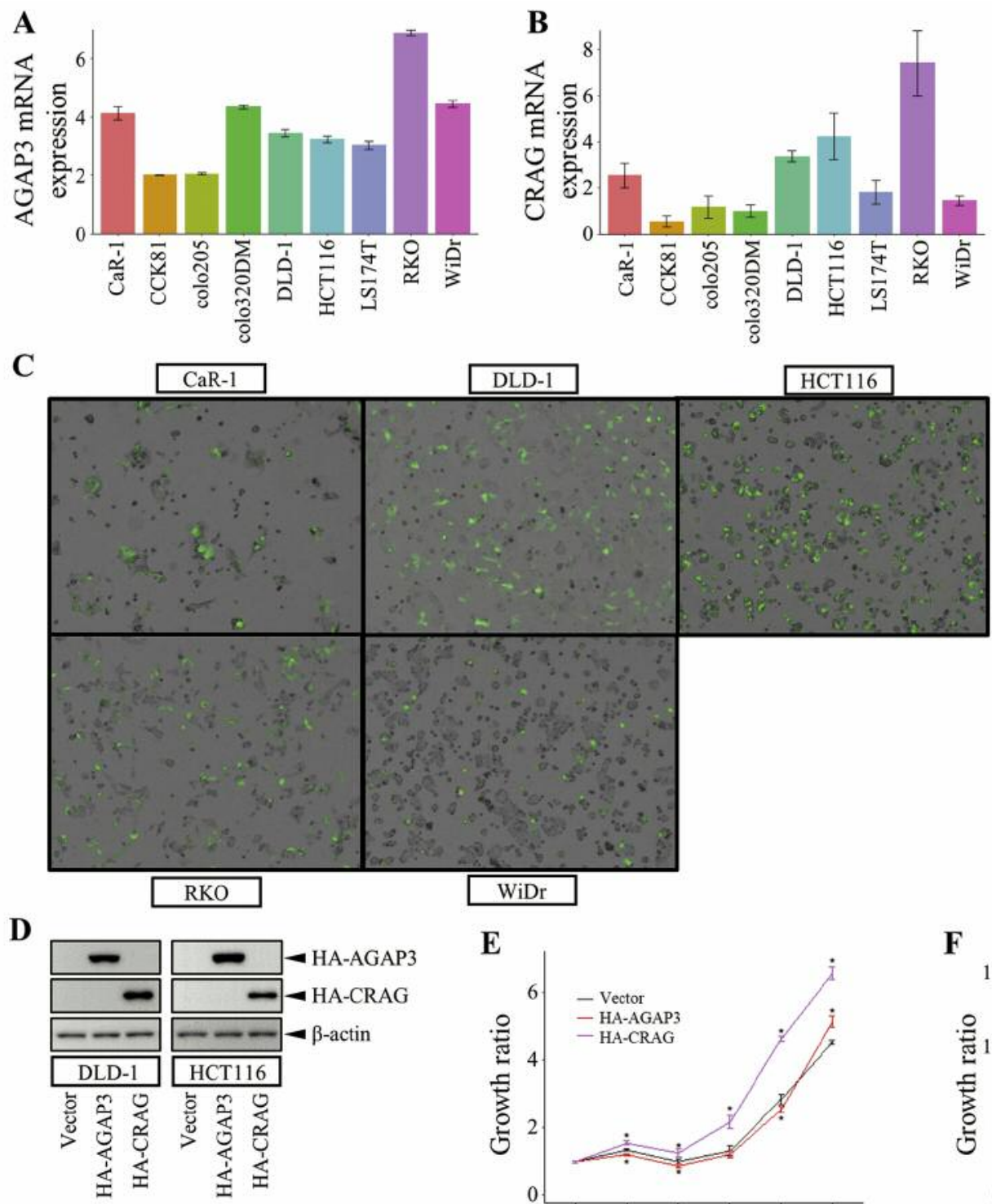

\begin{tabular}{|l|l|}
\hline DLD-1 & HCT116 \\
\hline
\end{tabular}

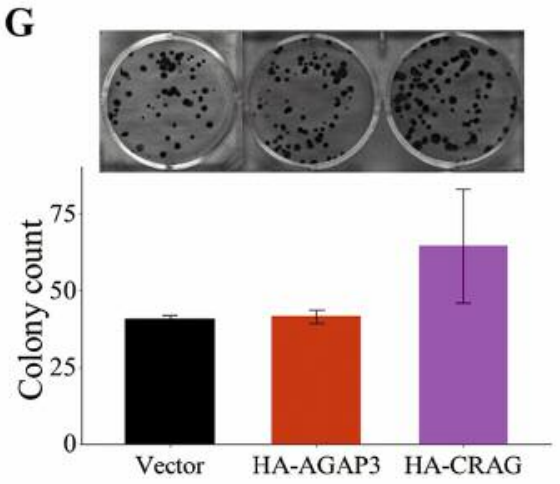

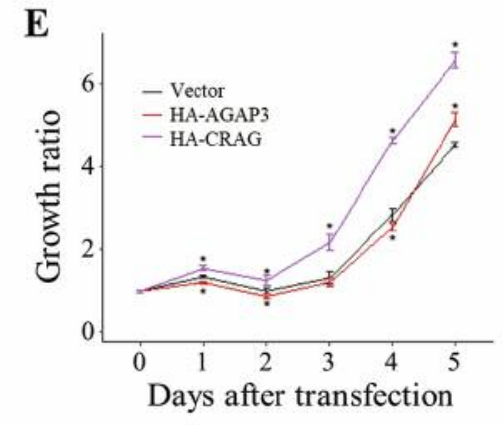

$\mathbf{H}$

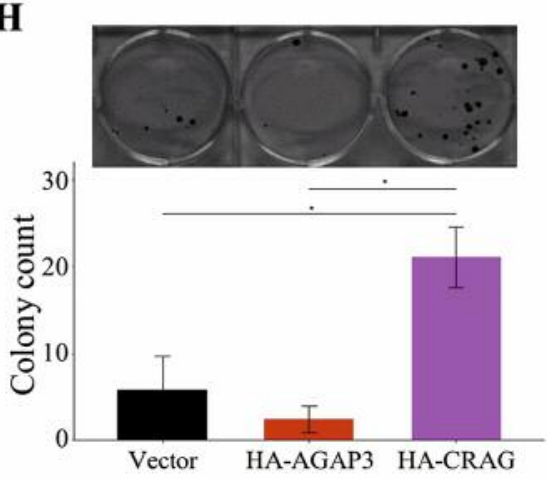

F

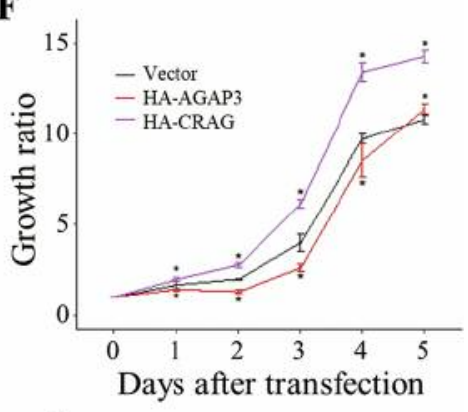

I

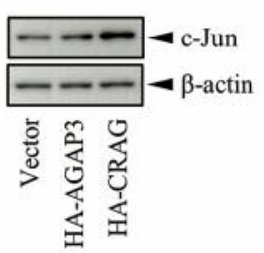

Figure 3. Overexpression of AGAP3 and CRAG. A: AGAP3 mRNA expression in CRC cell lines. B: CRAG mRNA expression in CRC cell lines. C: Evaluation of transfection efficacy using an expression vector carrying EGFP. D: WB to confirm overexpression of HA-AGAP3 and HA-CRAG. E: MTT assay in DLD-1 cells. F: MTT assay in HCT116 cells. G: Colony formation assay in DLD-1 cells. H: Colony formation assay in HCT116 cells. I: WB for c-Fos and c-Jun using DLD-1 cells. 
A

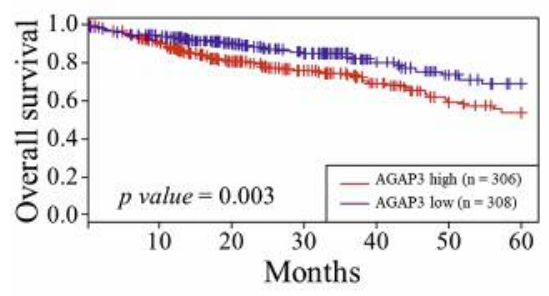

D

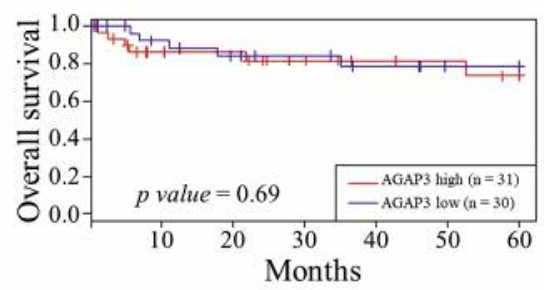

B

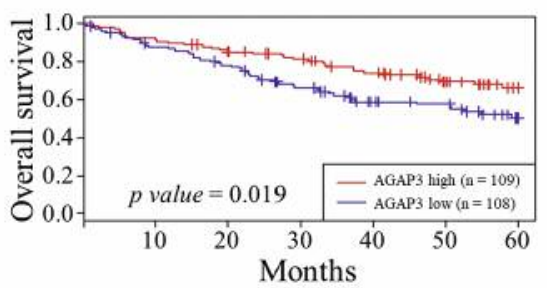

C

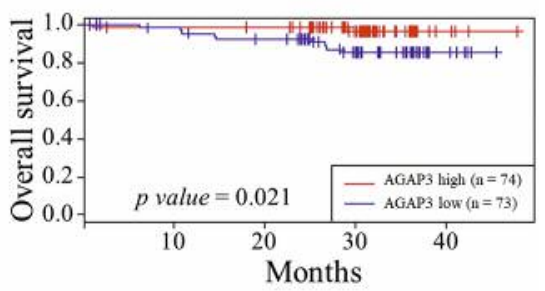

$\mathbf{E}$

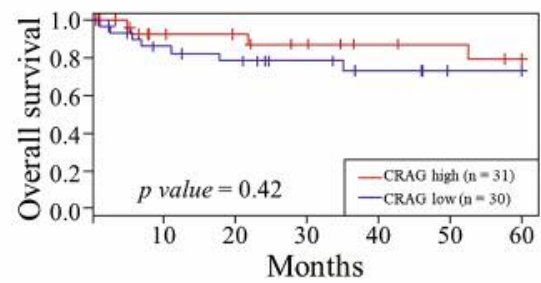

Figure 4. Prognostic impact of AGAP3 and CRAG mRNA expression. A: Survival curves for AGAP3 mRNA expression in TCGA dataset. B: Survival curves for AGAP3 mRNA expression in the GSE17538 dataset. C: Survival curves for AGAP3 mRNA expression in the GSE21815 dataset. D: Survival curves for AGAP3 mRNA expression in our clinical cohort. E: Survival curves for CRAG mRNA expression in our clinical cohort.

promoted the degradation of polyglutamine protein (polyQ) through the ubiquitin-proteasome pathway in neuronal cells (7). Nagashima et al. revealed that CRAG protected neuronal cells against polyQ via the activation of c-Fos-dependent AP-1 (8). Additionally, the cancer incidence, including CRC in patients with polyQ disease, such as Huntington's disease, is significantly lower than expected $(12,13)$. These data support our hypothesis that $C R A G$ contributes to CRC carcinogenesis.

TCGA dataset indicated that CNA in chromosomal arms had already occurred in the early stage of CRC. The focal DNA copy number in the $A G A P 3$ locus and $A G A P 3$ mRNA expression were positively correlated. AGAP3 mRNA expression was significantly higher in CRC tissue and colorectal adenoma tissue than in normal colorectal tissue; furthermore, AGAP3 mRNA expression was equal among pathological stages. These data suggest that $A G A P 3$ mRNA expression is increased in the initial phase of carcinogenesis as a result of DNA copy number gain in the AGAP3 locus due to copy number gain of Chr.7q. The prognostic impact of $A G A P 3$ expression, which was evaluated regardless of the splicing variants, differed among public datasets. In our own CRC dataset, patient prognosis did not depend on AGAP3 or CRAG mRNA expression. This discrepancy indicates that $A G A P 3$ and $C R A G$ may contribute to carcinogenesis rather than to progression of CRC, which has already acquired malignant transformation. Additionally, the lack of a significant association between $A G A P 3$ or $C R A G$ mRNA expression and clinicopathological features strengthens this theory.

In a previous study, CRAG induced c-Fos elevation, which is one of the components of AP-1 in neuronal cells (8). AP-1 expression is reportedly altered in several cancers (14-20).
AP-1 associates with several cancer-associated pathways interacting with VEGF, p21, p53, cyclin D1, TGF- $\beta$, ZEB2, EGFR, Cox-2 and so on (21-26). In terms of CRC, Hu L et al. showed that tissue factor/factor VIIa/protease-activated receptor 2 (TF/FVIIa/PAR2) signaling promoted cell proliferation and migration via AP-1 (27). Zhang HS et al. and Peng Y et al. showed that AP-1 positively regulated cyclin D1 and promoted CRC cell proliferation $(28,29)$. In this study, $C R A G$ overexpression clearly up-regulated c-Jun, one of the components of AP-1. Thus, the copy number gain of $\mathrm{Chr} .7 \mathrm{q}$ and the consequent increase in CRAG expression should be a driver of CRC carcinogenesis by promoting cell proliferation via $\mathrm{AP}-1$.

This study has several limitations that must be acknowledged. First, the expression and clinical significance of each variant of $A G A P 3$ were not evaluated due to lack of classified expression data by variants in public datasets. Second, in our clinical cohort, the correlation between $A G A P 3$ and $C R A G$ mRNA expression and the significant difference in CRAG mRNA expression between CRC tissue and normal colorectal tissue were not obtained, probably due to the limited sample size. Finally, the expression and localization of the CRAG protein have not been uncovered because of the absence of a specific antibody for CRAG.

In conclusion, our study suggests that $C R A G$, a splicing variant of $A G A P 3$, plays an important role in CRC development via AP-1 activation.

\section{Conflicts of Interest}

The Authors declare no competing financial interests. 
Table II. Association between AGAP3 or CRAG expression and clinicopathological parameters in our clinical cohort.

\begin{tabular}{|c|c|c|c|c|c|c|}
\hline $\begin{array}{l}\text { Clinicopathological } \\
\text { parameters }\end{array}$ & $\begin{array}{l}A G A P 3 \text { high } \\
\quad \mathrm{n}=31\end{array}$ & $\begin{array}{c}A G A P 3 \text { low } \\
\mathrm{n}=30\end{array}$ & $p$-Value & $\begin{array}{c}C R A G \text { high } \\
\mathrm{n}=31\end{array}$ & $\begin{array}{c}C R A G \text { low } \\
\mathrm{n}=30\end{array}$ & $p$-Value \\
\hline \multicolumn{7}{|l|}{ Age } \\
\hline$\leq 65$ years old & 13 & 10 & \multirow[t]{2}{*}{0.600} & 11 & 12 & \multirow[t]{2}{*}{0.795} \\
\hline$>65$ years old & 18 & 20 & & 20 & 18 & \\
\hline \multicolumn{7}{|l|}{ Gender } \\
\hline Male & 22 & 17 & \multirow[t]{2}{*}{0.293} & 18 & 21 & \multirow[t]{2}{*}{0.426} \\
\hline Female & 9 & 13 & & 13 & 9 & \\
\hline \multicolumn{7}{|l|}{ Tumor size } \\
\hline$<5 \mathrm{~cm}$ & 16 & 15 & \multirow[t]{2}{*}{1.000} & 15 & 16 & \multirow[t]{2}{*}{0.792} \\
\hline$\geq 5 \mathrm{~cm}$ & 13 & 13 & & 14 & 12 & \\
\hline \multicolumn{7}{|l|}{$\mathrm{T}$} \\
\hline $1 / 2$ & 7 & 12 & \multirow[t]{2}{*}{0.174} & 7 & 12 & \multirow[t]{2}{*}{0.174} \\
\hline $3 / 4$ & 24 & 18 & & 24 & 18 & \\
\hline \multicolumn{7}{|l|}{$\mathrm{N}$} \\
\hline Negative & 14 & 19 & \multirow[t]{2}{*}{0.202} & 16 & 17 & \multirow[t]{2}{*}{0.799} \\
\hline Positive & 17 & 11 & & 15 & 13 & \\
\hline \multicolumn{7}{|l|}{ M } \\
\hline Negative & 28 & 30 & \multirow[t]{2}{*}{0.278} & 28 & 30 & \multirow[t]{2}{*}{0.278} \\
\hline Positive & 3 & 0 & & 3 & 0 & \\
\hline \multicolumn{7}{|l|}{ Dukes classification } \\
\hline A & 7 & 11 & \multirow[t]{4}{*}{0.344} & 9 & 9 & \multirow[t]{4}{*}{1.000} \\
\hline $\mathrm{B}$ & 7 & 7 & & 7 & 7 & \\
\hline $\mathrm{C}$ & 12 & 11 & & 12 & 11 & \\
\hline $\mathrm{D}$ & 5 & 1 & & 3 & 3 & \\
\hline \multicolumn{7}{|l|}{ Tumor location } \\
\hline Right colon & 12 & 11 & \multirow[t]{2}{*}{1.000} & 11 & 12 & \multirow[t]{2}{*}{0.795} \\
\hline Left colon/rectum & 19 & 19 & & 20 & 18 & \\
\hline \multicolumn{7}{|l|}{ Histological type } \\
\hline Well & 11 & 15 & \multirow[t]{3}{*}{0.513} & 11 & 15 & \multirow[t]{3}{*}{0.513} \\
\hline Mod & 18 & 14 & & 18 & 14 & \\
\hline Por & 2 & 1 & & 2 & 1 & \\
\hline Lymphatic invasion & & & & & & \\
\hline Negative & 16 & 17 & 0.799 & 15 & 18 & 0.444 \\
\hline Positive & 15 & 13 & & 16 & 12 & \\
\hline Venous invasion & & & & & & \\
\hline Negative & 22 & 22 & 1.000 & 22 & 22 & 1.000 \\
\hline Positive & 9 & 8 & & 9 & 8 & \\
\hline
\end{tabular}

T: Tumor depth; N: lymph node metastasis; M: distant metastasis; $\mathrm{n}$ : case number.

\section{Acknowledgements}

The expression constructs with the pCMV5 vector for AGAP3 tagged with HA and CRAG tagged with HA were graciously provided by Shun Nagashima and Shigeru Yanagi, Laboratory of Molecular Biochemistry, School of Life Sciences, Tokyo University of Pharmacy and Life Sciences, Japan. The Authors thank Kazumi Oda, Michiko Kasagi and Sachiko Sakuma for their excellent technical assistance in this study. This work was supported in part by the following grants and foundations: Japan Society for the Promotion of Science Grant-in-Aid for Scientific Research (Grant No.: 15H05912, 15H05707, hp160219, hp170227, and hp170227).

\section{References}

1 Allemani C, Weir HK, Carreira H, Harewood R, Spika D, Wang XS, Bannon F, Ahn JV, Johnson CJ, Bonaventure A, MarcosGragera R, Stiller C, Azevedo e Silva G, Chen WQ, Ogunbiyi
OJ, Rachet B, Soeberg MJ, You H, Matsuda T, Bielska-Lasota M, Storm H, Tucker TC and Coleman MP: Global surveillance of cancer survival 1995-2009: analysis of individual data for $25,676,887$ patients from 279 population-based registries in 67 countries (CONCORD-2). Lancet 385: 977-1010, 2015.

2 Vogelstein B, Fearon ER, Hamilton SR, Kern SE, Preisinger AC, Leppert M, Nakamura Y, White R, Smits AM, and Bos JL: Genetic alterations during colorectal-tumor development. N Engl J Med 319: 525-532, 1988.

3 Uchi R, Takahashi Y, Niida A, Shimamura T, Hirata H, Sugimachi K, Sawada G, Iwaya T, Kurashige J, Shinden Y, Iguchi T, Eguchi H, Chiba K, Shiraishi Y, Nagae G, Yoshida K, Nagata Y, Haeno H, Yamamoto H, Ishii H, Doki Y, Inuma H, Sasaki S, Nagayama S, Yamada K, Yachida S, Kato M, Shibata T, Oki E, Saeki H, Shirabe K, Oda Y, Maehara Y, Komune S, Mori M, Suzuki Y, Yamamoto K, Aburatani H, Ogawa S, Miyano S and Mimori K: Integrated Multiregional Analysis Proposing a New Model of Colorectal Cancer Evolution. PLoS Genet 12: e1005778, 2016. 
4 Saito T, Niida A, Uchi R, Hirata H, Komatsu H, Sakimura S, Hayashi S, Nambara S, Kuroda Y, Ito S, Eguchi H, Masuda T, Sugimachi K, Tobo T, Nishida H, Daa T, Chiba K, Shiraishi Y, Yoshizato T, Kodama M, Okimoto T, Mizukami K, Ogawa R, Okamoto K, Shuto M, Fukuda K, Matsui Y, Shimamura T, Hasegawa T, Doki Y, Nagayama S, Yamada K, Kato M, Shibata T, Mori M, Aburatani H, Murakami K, Suzuki Y, Ogawa S, Miyano S and Mimori K: A temporal shift of the evolutionary principle shaping intratumor heterogeneity in colorectal cancer. Nat Commun 9: 2884, 2018.

5 Sato K, Masuda T, Hu Q, Tobo T, Kidogami S, Ogawa Y, Saito T, Nambara S, Komatsu H, Hirata H, Sakimura S, Uchi R, Hayashi N, Iguchi T, Eguchi H, Ito S, Nakagawa T and Mimori K: Phosphoserine Phosphatase Is a Novel Prognostic Biomarker on Chromosome 7 in Colorectal Cancer. Anticancer Res 37: 2365-2371, 2017.

6 Trop-Steinberg S and Azar Y: AP-1 Expression and its Clinical Relevance in Immune Disorders and Cancer. Am J Med Sci 353: 474-483, 2017.

7 Qin Q, Inatome R, Hotta A, Kojima M, Yamamura H, Hirai H, Yoshizawa T, Tanaka H, Fukami K and Yanagi S: A novel GTPase, CRAG, mediates promyelocytic leukemia proteinassociated nuclear body formation and degradation of expanded polyglutamine protein. J Cell Biol 172: 497-504, 2006.

8 Nagashima S, Fukuda T, Kubota Y, Sugiura A, Nakao M, Inatome R and Yanagi S: CRMP5-associated GTPase (CRAG) protein protects neuronal cells against cytotoxicity of expanded polyglutamine protein partially via c-Fos-dependent activator protein-1 activation. J Biol Chem 286: 33879-33889, 2011.

9 Kurashige J, Hasegawa T, Niida A, Sugimachi K, Deng N, Mima K, Uchi R, Sawada G, Takahashi Y, Eguchi H, Inomata M, Kitano S, Fukagawa T, Sasako M, Sasaki H, Sasaki S, Mori M, Yanagihara K, Baba H, Miyano S, Tan P and Mimori K: Integrated molecular profiling of human gastric cancer identifies DDR2 as a potential regulator of peritoneal dissemination. Sci Rep 6: 22371, 2016.

10 Nambara S, Masuda T, Nishio M, Kuramitsu S, Tobo T, Ogawa Y, Hu Q, Iguchi T, Kuroda Y, Ito S, Eguchi H, Sugimachi K, Saeki H, Oki E, Maehara Y, Suzuki A and Mimori K: Antitumor effects of the antiparasitic agent ivermectin via inhibition of Yesassociated protein 1 expression in gastric cancer. Oncotarget 8 : 107666-107677, 2017.

$11 \mathrm{Oku}$ Y and Huganir RL: AGAP3 and Arf6 regulate trafficking of AMPA receptors and synaptic plasticity. J Neurosci 33: 12586-12598, 2013.

$12 \mathrm{Ji}$ J, Sundquist K and Sundquist J: Cancer incidence in patients with polyglutamine diseases: a population-based study in Sweden. Lancet Oncol 13: 642-648, 2012.

13 Coarelli G, Diallo A, Thion MS, Rinaldi D, Calvas F, Boukbiza OL, Tataru A, Charles P, Tranchant C, Marelli C, Ewenczyk C, Tchikviladze M, Monin ML, Carlander B, Anheim M, Brice A, Mochel F, Tezenas du Montcel S, Humbert S and Durr A: Low cancer prevalence in polyglutamine expansion diseases. Neurology 88: 1114-1119, 2017.

14 Bamberger AM, Methner C, Lisboa BW, Stadtler C, Schulte HM, Loning T and Milde-Langosch K: Expression pattern of the AP-1 family in breast cancer: association of fosB expression with a well-differentiated, receptor-positive tumor phenotype. Int J Cancer 84: 533-538, 1999.

15 Bamberger AM, Milde-Langosch K, Rossing E, Goemann C and Loning T: Expression pattern of the AP-1 family in endometrial cancer: correlations with cell cycle regulators. J Cancer Res Clin Oncol 127: 545-550, 2001.
16 Mahner S, Baasch C, Schwarz J, Hein S, Wolber L, Janicke F and Milde-Langosch $\mathrm{K}$ : C-Fos expression is a molecular predictor of progression and survival in epithelial ovarian carcinoma. Br J Cancer 99: 1269-1275, 2008.

17 Zhou L, Zhang JS, Yu JC, Cui QC, Zhou WX, Kang WM and Ma ZQ: Negative association of c-fos expression as a favorable prognostic indicator in gastric cancer. Arch Med Res 41: 201206, 2010.

18 Staber PB, Linkesch W, Zauner D, Beham-Schmid C, Guelly C, Schauer S, Sill H and Hoefler G: Common alterations in gene expression and increased proliferation in recurrent acute myeloid leukemia. Oncogene 23: 894-904, 2004.

19 Yang MY, Liu TC, Chang JG, Lin PM and Lin SF: JunB gene expression is inactivated by methylation in chronic myeloid leukemia. Blood 101: 3205-3211, 2003.

20 Leventaki V, Drakos E, Karanikou M, Psatha K, Lin P, Schlette E, Eliopoulos A, Vassilakopoulos TP, Papadaki H, Patsouris E, Medeiros LJ and Rassidakis GZ: c-JUN $N$-terminal kinase (JNK) is activated and contributes to tumor cell proliferation in classical Hodgkin lymphoma. Hum Pathol 45: 565-572, 2014.

21 Kidd M, Hinoue T, Eick G, Lye KD, Mane SM, Wen Y and Modlin IM: Global expression analysis of ECL cells in Mastomys natalensis gastric mucosa identifies alterations in the AP-1 pathway induced by gastrin-mediated transformation. Physiol Genomics 20: 131-142, 2004.

22 Kuo YR, Wu WS and Wang FS: Flashlamp pulsed-dye laser suppressed TGF-beta1 expression and proliferation in cultured keloid fibroblasts is mediated by MAPK pathway. Lasers Surg Med 39: 358-364, 2007.

23 Zhao C, Qiao Y, Jonsson P, Wang J, Xu L, Rouhi P, Sinha I, Cao Y, Williams C and Dahlman-Wright K: Genome-wide profiling of AP-1-regulated transcription provides insights into the invasiveness of triple-negative breast cancer. Cancer Res 74: 3983-3994, 2014.

24 Shaulian E and Karin M: AP-1 as a regulator of cell life and death. Nat Cell Biol 4: E131-136, 2002.

25 Lopez-Bergami P, Lau E, and Ronai Z: Emerging roles of ATF2 and the dynamic AP1 network in cancer. Nat Rev Cancer 10: 65$76,2010$.

26 Konstantinopoulos PA, Vandoros GP, Sotiropoulou-Bonikou G, Kominea A and Papavassiliou AG: NF-kappaB/PPAR gamma and/or AP-1/PPAR gamma 'on/off' switches and induction of $\mathrm{CBP}$ in colon adenocarcinomas: correlation with COX-2 expression. Int J Colorectal Dis 22: 57-68, 2007.

$27 \mathrm{Hu} \mathrm{L}$, Xia L, Zhou H, Wu B, Mu Y, Wu Y and Yan J: TF/FVIIa/PAR2 promotes cell proliferation and migration via PKCalpha and ERK-dependent c-Jun/AP-1 pathway in colon cancer cell line SW620. Tumour Biol 34: 2573-2581, 2013.

28 Zhang HS, Yan B, Li XB, Fan L, Zhang YF, Wu GH, Li M and Fang J: PAX2 protein induces expression of cyclin D1 through activating AP-1 protein and promotes proliferation of colon cancer cells. J Biol Chem 287: 44164-44172, 2012.

29 Peng Y, Li H, Wu M, Wang X, Fan S, Liu F, Xiang B, Guo Q, Tang $X$ and Shen S: NGX6 inhibits AP-1 and Ets-1 expression and down-regulates cyclin D1 in human colorectal cancer. Acta Biochim Biophys Sin (Shanghai) 41: 504-514, 2009.

Received November 16, 2018

Revised November 20, 2018

Accepted November 21, 2018 